\title{
Sweden: Financial Sector Assessment Program Update-Technical Note on Contingent Claims Analysis Approach to Measure Risk and Stress Test the Swedish Banking Sector
}

This technical note on Contingent Claims Analysis Approach to Measure Risk and Stress Test the Swedish Banking Sector was prepared by a staff team of the International Monetary Fund as background documentation for the periodic consultation with the member country. It is based on the information available at the time it was completed in September, 2011. The views expressed in this document are those of the staff team and do not necessarily reflect the views of the government of Sweden or the Executive Board of the IMF.

The policy of publication of staff reports and other documents by the IMF allows for the deletion of market-sensitive information.

\author{
Copies of this report are available to the public from \\ International Monetary Fund • Publication Services \\ $70019^{\text {th }}$ Street, N.W. • Washington, D.C. 20431 \\ Telephone: (202) 623-7430 • Telefax: (202) 623-7201 \\ E-mail: publications@imf.org Internet: http://www.imf.org
}

\section{International Monetary Fund Washington, D.C.}


FinANCIAL SECtor ASSESSMENT PROGRAM UpdATE

\section{SWEDEN}

CONTINGEnT Claims AnAlysis APPROACH to MEASURE RISK AND STRESS TEST THE Swedish BANKING SECTOR

TECHNICAL NOTE

SEPTEMBER 2011

INTERNATIONAL MONETARY FUND

MONETARY AND CAPITAL MARKETS DEPARTMENT 


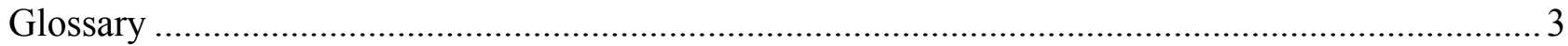

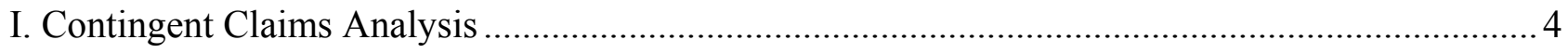

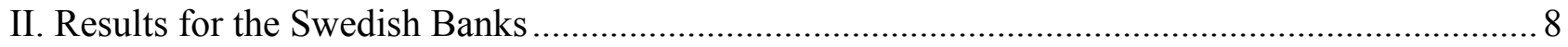

III. Systemic CCA Analysis of the Swedish Banking System............................................... 13

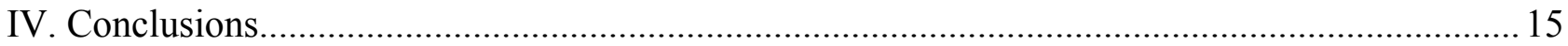

Box

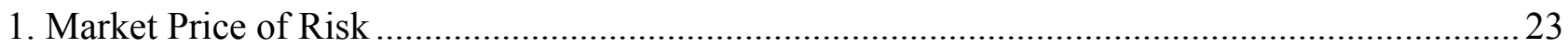

Tables

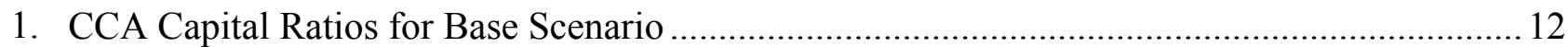

2. Expected Losses and Market Value of Equity (Percent change from Base Scenario) and CCA Capital Tatios (In percent) ................................................................ 13

3. Market Sharpe Ratio Scenarios.......................................................................................... 26

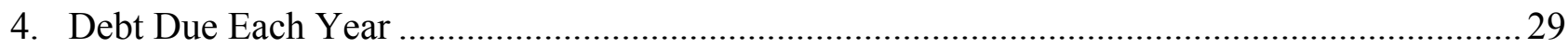

Figures

1a. CCA Capital Ratio (Equity Market Capitalization/Market Value of Assets)............................ 9

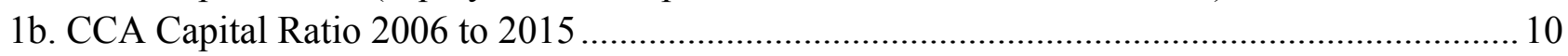

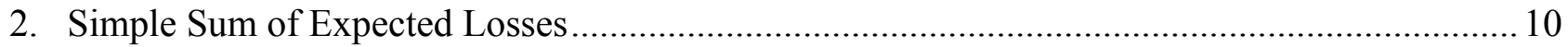

3. Credit Spreads (one year, basis points, weighted by bank assets) ........................................ 11

4. Banking Sector-Total Sum and Multivariate Distribution Function

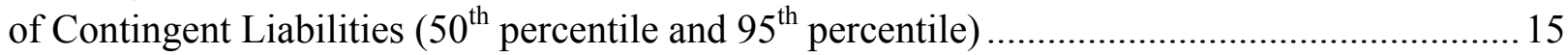

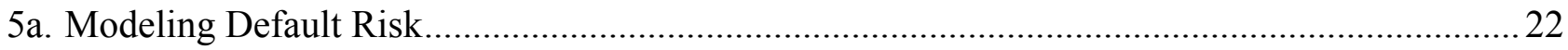

5b. Actual vs. Risk Neutral Default Probabilities...................................................................... 23

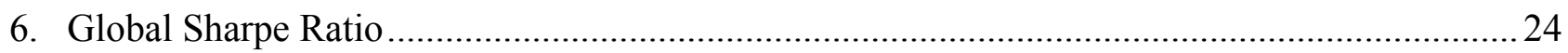

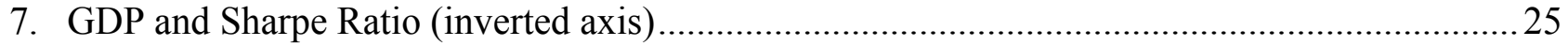

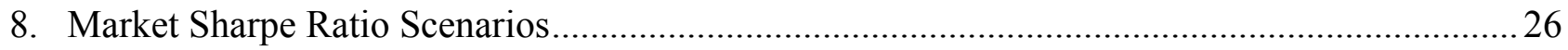

Appendixes

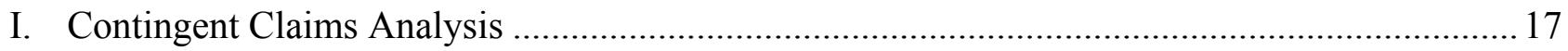

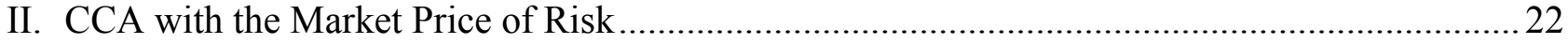

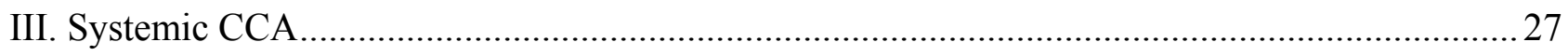

IV. Funding Cost Using CCA and Debt Due Each Year ........................................................29

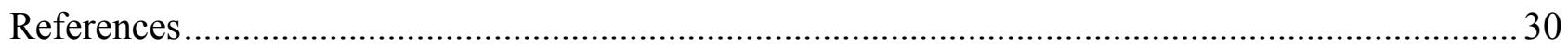




\section{GLOSSARY}

$\begin{array}{ll}\text { BSM } & \text { Black-Scholes-Merton } \\ \text { CCA } & \text { Contingent claims analysis } \\ \text { D2D } & \text { Distance to distress } \\ \text { EAD } & \text { Exposure at default } \\ \text { EL } & \text { Expected loss } \\ \text { EDF } & \text { Expected default frequency } \\ \text { ES } & \text { Expected shortfall } \\ \text { EVT } & \text { Extreme value theory } \\ \text { FSAP } & \text { Financial Sector Assessment Program } \\ \text { GEV } & \text { Generalized extreme value } \\ \text { LGD } & \text { Loss given default } \\ \text { M KMV } & \text { Moody's KMV } \\ \text { MPR } & \text { Market price of risk } \\ \text { PD } & \text { Probability of default } \\ \text { RWA } & \text { Risk-weighted assets } \\ \text { SEK } & \text { Swedish krona } \\ \text { SR } & \text { Sharpe ratio } \\ \text { VaR } & \text { Value-at-risk }\end{array}$




\section{Contingent Claims Analysis ApProach to Measure Risk and Stress Test THE SWEDISH BANKING SECTOR ${ }^{1}$}

\section{This note describes the application of the contingent claims analysis (CCA) and systemic CCA to the top four commercial banks in Sweden, both historically and for four} forward-looking stress test scenarios. This framework calibrates the risk-adjusted balance sheets for individual financial institutions and their associated expected losses as well as the dependence between them in order to estimate the joint expected losses in a multivariate framework. The framework uses daily data from 2007 through 2010. Four stress test scenarios, agreed with the authorities under the FSAP Update, and results of the balance sheet stress tests are used with the systemic CCA model to estimate bank-by-bank outputs for the 2011 to 2015 period. Outputs include expected losses to creditors, changes in funding costs, CCA capital ratios, and a capital shortfall measure. In addition, the Systemic CCA model for the four banks is estimated historically; expected and tail-risk expected losses to creditors are estimated. Results show banks are resilient to shocks and these results are consistent with the balance sheet stress test results.

\section{Contingent Claims Analysis}

2. The CCA framework is a risk-adjusted balance sheet concept. It is an integrated framework relating bank asset values to equity value, default risk, and bank funding costs. In the risk-adjusted balance sheet framework, the total market value of bank assets is equal to the sum of its market value equity and its "risky debt" over a specific time horizon. ${ }^{2}$ Risky debt is composed of two parts, the default-free value of debt and deposits minus the "expected loss to bank creditors" from default over a specific time horizon (see Appendix I).

\section{What is the difference between accounting and risk-adjusted balance sheets?}

3. In the traditional way of analyzing bank balance sheets, a change in accounting assets has a one-for-one change in book equity. The traditional bank accounting balance sheet has accounting assets on the left and liabilities consisting of book equity and book value of debt and deposits. When assets change, the full change affects book equity.

\footnotetext{
${ }^{1}$ This note was prepared by Dale Gray and Andy Jobst, with help from Stephanie Stolz and useful comments from Andrea Maechler. The authors would like to thank Hovick Shahnazarian and Martin Johansson of the Riksbank for very useful insights, comments, and suggestions.

${ }^{2}$ Contingent claims analysis (CCA) is a generalization of the option pricing theory pioneered by Black and Scholes (1973), as well as Merton (1973). The values of liabilities (equity and risky debt) derive their value from assets; they are contingent claims on assets. When applied to the analysis of credit risk, it is commonly called the Merton Model, which is based on the Black-Scholes-Merton (BSM) framework of capital structure-based option pricing theory (Merton,1974).
} 


\begin{tabular}{ll}
\hline & Traditional Bank Accounting Balance Sheet \\
\hline Assets & Liabilities \\
Accounting assets & Debt and deposits \\
(Cash, reserves, loans, credits, other exposures) & Book equity \\
\hline
\end{tabular}

4. In traditional bank stress testing, the concept of "expected losses" is related to loans and exposures on the asset side of the bank's balance sheet. For example, expected losses are associated with loans to corporations, or mortgage loans, or a derivative exposure, etc. This traditional expected loss is frequently calculated as a probability of default (PD) times a loss given default (LGD) times the exposure at default (EAD). The expected losses to various loans or other exposures are aggregated (using certain assumptions regarding correlation, etc.) and used as an input into loss distribution calculations, which are in turn used for the estimation of regulatory capital. (Note, CCA type models for corporate, such as MKMV, are frequently used to estimate PDs, LGDs, etc.)

5. In the risk-adjusted balance sheet, changes in assets are directly linked to changes in market value of equity and the expected losses to creditors. For a bank, the key risk-adjusted balance sheet relationships are:

Bank assets $=$ Bank market value of equity + Bank risky debt and deposits

where, Bank risky debt and deposits $=$ Default-free value of debt and deposits - Expected losses to bank creditors

In the risk-adjusted balance sheet framework, a decline in the value of assets leads to less than oneto-one decline in the market value of equity; the amount of change in equity depends on the degree of financial distress in the bank. The decline in bank assets simultaneously leads to an increase in the value of expected losses to creditors. The amount of increase can be very high when banks are in severe financial distress.

\begin{tabular}{ll}
\hline & Risk-Adjusted (CCA) Bank Balance Sheet \\
\hline Assets & Liabilities \\
Market value of assets & Risky debt \\
(Cash, reserves, value of "risky" assets) & (= Default-free Value of Debt and Deposits minus \\
& Expected Losses to Bank Creditors) \\
& Market value of equity \\
\hline
\end{tabular}

6. In the risk-adjusted (CCA) balance sheet of the bank, the "expected loss to bank creditors" relates to the total debt and deposits on the full bank balance sheet. This expected loss to bank creditors can be viewed as a probability of bank default times a loss given default times an "exposure" represented by the default free value of the bank's total debt and deposits (formula is in Appendix I). The expected loss to creditors is a "risk exposure" in the risk-adjusted balance 
sheet. Note that the risk-adjusted bank balance sheet and the traditional accounting bank balance sheet are related. The accounting balance sheet can be "derived" from the special case of the riskadjusted balance sheet - the case where there is uncertainty is set to zero (i.e., bank's assets have no volatility). With zero volatility on the balance sheet, the expected loss to bank creditors goes to zero and equity becomes book equity. The "risk exposure" becomes zero. " "You can't get a risk exposure from an accounting balance sheet or income statement" — as professor Robert Merton has emphasized).

\section{The risk-adjusted (CCA) balance sheet of the banks can quantify the impact on bank borrowing cost of higher (or lower) levels of equity, the impact of changes in global risk appetite, and of government guarantees.}

- $\quad$ Lower levels of the market value of equity are directly related to higher bank funding costs. There is increasing interest in indicators that use market value of equity as measures of financial fragility. ${ }^{4}$ The ratio of market value of equity to market value of bank assets is a very useful indicator (CCA capital ratio). This ratio is related to bank funding costs and the level of this ratio will be calculated and its level can be compared to the level in earlier crisis periods.

- $\quad$ The CCA balance sheet has another advantageous feature. The impact of changes in global or regional risk appetite on the values of bank-expected losses to creditors, bank funding costs, and bank equity can be measured. Lower risk appetite causes investors to flee from "risky" investments to safer forms of investment, this raises borrowing costs around the world for corporate, sovereign, household borrowers, etc. Since CCA framework quantifies the impact of changes in risk appetite, stress test scenarios can include stressing changes in global or region risk appetite.

- During the crisis, implicit and explicit government guarantees had an important impact on reducing bank borrowing costs (and shifting risk to the sovereign balance sheet), which can be measured in the CCA framework.

\footnotetext{
${ }^{3}$ See Gray, Merton, Bodie (2007 and 2008), and Gray and Malone (2008).

${ }^{4}$ For example, see Haldane (2011) "Market-based metrics of bank solvency count be based around the market rather than book value of capital....e.g., ratio of a bank's market capitalization to its total assets. ... Market-based measures of capital offered clear advance signals of impending distress beginning April 2007.....replacing the book value of capital by the market value lowers errors by half. Market measures provide both fewer false positives and more reliable advance warnings of future banking distress."
} 
8. It is important to measure expected losses to bank creditors in order to understand the drivers of changes in bank funding costs and for financial stability. Higher bank borrowing costs lead to higher lending rates for corporates and households, to credit rationing, and lower credit growth. This can have a negative impact on economic output, which can in turn feed back, causing further distress in the banking system. Higher expected losses to creditors raise bank borrowing costs. Lenders may cut off credit and induce severe liquidity problems that can spread through the whole financial system. Bank creditors can incur losses, which might contribute to financial instability. Higher expected systemic losses can transfer risk to the government via guarantees and costs of resolving failed banks.

\section{How can CCA balance sheets be used in stress testing?}

9. There are three ways in which macro variables can be used in stress testing individual bank CCA balance sheets. First, the outputs from traditional stress tests (whether top-down or bottom-up) where macro factors affect PDs, LGDs, exposures, etc., can be used as inputs into the calibrated bank CCA model. These traditional stress test outputs provide changes in bank net income, which directly link to changes in the bank asset value in the CCA model, which will produce outputs such as expected losses to creditors, funding cost changes and CCA capital ratio (market value of equity to market value of assets), and other useful outputs. The second way to link macro variables to CCA is to estimate the historical relationship of the macro factors to the expected losses to creditors (or other CCA risk indicators) using econometrics, then project changes in the future using the stress test macro scenarios (as was done in the United States FSAP, IMF 2010b). The third way to link macro variables is to estimate the historical relationships of the macro factors to changes in the bank market value of assets (this is done in MKMV global correlation and portfolio models, and an example is in IMF WP (2007)). This technical note will use the first method as described below.

\section{The individual bank CCA models are used to assess the impact of changes in bank} assets, associated change in asset volatility, and the impact of changes in global risk appetite on expected losses to creditors, bank funding costs, and CCA capital ratio for four scenarios. The balance sheet stress test outputs ${ }^{5}$ provide annual changes in bank net income due to profits, loan losses, tax, and dividend payments from 2011 to 2015 linked to the four stress test scenarios. These changes are used as inputs, which directly cause changes in each individual bank asset value in the CCA model. (This is described below in Section II and details are in Appendix I). Changes in the bank's asset, in turn, affect bank-asset volatility. Adjusted asset plus adjusted volatility inserted into CCA spread formula and applied to debt due in next year gives additional incremental funding cost changes year by year. In the last stage of the individual bank CCA stress testing, the impact of changes in global risk appetite are included (details are in Appendix II). Bank-by-bank outputs are the expected losses, funding cost changes, and CCA capital ratio.

\footnotetext{
${ }^{5}$ Sweden FSAP Update Technical Note, Stress Testing of the Banking Sector.
} 
11. Systemic risk indicators can be calculated using the Systemic CCA framework. This framework analyzes the dependence between banks for the system as a whole, providing measures of joint expected losses to creditors, joint market value of banking system capital (and even measures of market implied government contingent liabilities to the banking system, as reported in the Sweden 2010 Article IV SIP, IMF 2010a). Systemic CCA model is applied to the Swedish banking system (in Section III, and more details in Appendix III). Historical trends in the median and tail-risk systemic losses are estimated and described. The individual bank losses are used with the systemic CCA and the joint system losses are estimated (the median and tail risk systemic losses).

\section{RESULTS FOR THE SWEDISH BANKS}

\section{Banking system stress tests using CCA}

12. The CCA models for each of the four banks were calibrated first and then used for the stress testing using CCA. The CCA model for each bank used equity market and balance sheet information (including some inputs from Moody's KMV Credit Edge for each bank) to calibrate the key parameters of the CCA model (bank asset level, asset volatility, bank debt distress barrier, skew, kurtosis, and a volatility-adjustment parameter). The calibrated model for December 30, 2010 was used as the starting point.

\section{The results of the balance sheet stress tests were used to estimate changes in bank} assets. Bank-by-bank profits before loan losses, and bank-by-bank loan losses, adjusted for taxes and dividends give the changes in bank assets for the four stress test scenarios each year 2011 to 2015 (the process is described in detail in Appendix I). Also, the global market price of risk (a measure of global risk appetite) was projected for each of the four scenarios (based on historical relationships to GDP, see Appendix II for details). Thus, the changes in bank assets (and associated change in bank-asset volatility) and the scenarios on the market price of risk are inputs to the CCA bank models and the outputs are the expected losses to creditors and market value of equity for each bank annually over the 2011 to 2015 period, from the base date of end 2010 .

\section{The next step is to estimate the changes in funding costs for each bank derived from} changes in credit spreads due to the changes in expected losses to creditors derived from the CCA model. Changes in funding costs come from the incremental funding cost spread formula which is $s_{\text {incremental }}=\left[-T^{-1} \ln \left(1-E L / B e^{-r T}\right)\right]-S_{\text {base }}$. Credit spread from the scenario (which is a function of expected loss, EL, bank default barrier, B, risk-free rate, $r$, and time horizon $\mathrm{T}$ equal to one year) minus the base credit spread (i.e., spread if bank assets remain unchanged) gives the incremental spread. This is multiplied by the incremental debt due each year (data in Appendix IV) to get the change in funding costs each year. After deducting the fraction of the funding cost that can be transferred to customers, the change in funding costs translates into an additional change in bank assets, which is inserted in the CCA model and the outputs are recalculated. The final outputs are: (i) expected losses to creditors; (ii) credit spreads; and, (iii) CCA capital ratio (market value of 
equity from the scenario output divided by the market value of assets for the same scenario). The final results thus include the changes in assets (due to changes in profits, loan losses, taxes and dividends), associated changes in asset volatility, impact of the change in the market price of risk, and the impact of the incremental funding cost changes.

\section{The ratio of equity capital (market capitalization) to the (market value) of assets is} shown to decline in the beginning before it increases for the adverse scenarios. See Figure $1 .^{6}$ The CCA capital ratios for the four banks in aggregate decline for the three adverse scenarios, but start increasing sooner in the Adverse 1 and 2 scenarios than in the Adverse 3 scenario as shown in Figure 1a. The CCA capital ratio by 2012 is 5.62 percent for the base scenario and 4.93 percent for the Adverse 3 scenario. From the perspective of a longer time period, the CCA capital ratios over the stress test period (ranging from 4.5 percent to 6 percent) are all significantly higher than the low of 3 percent reached in 2008 at the height of the crisis, but are significantly below the peak of 8.8 percent before the crisis in 2006 as shown in Figure $1 \mathrm{~b}$.

Figure 1a. Sweden: CCA Capital Ratio (Equity Market Capitalization/Market Value of Assets)

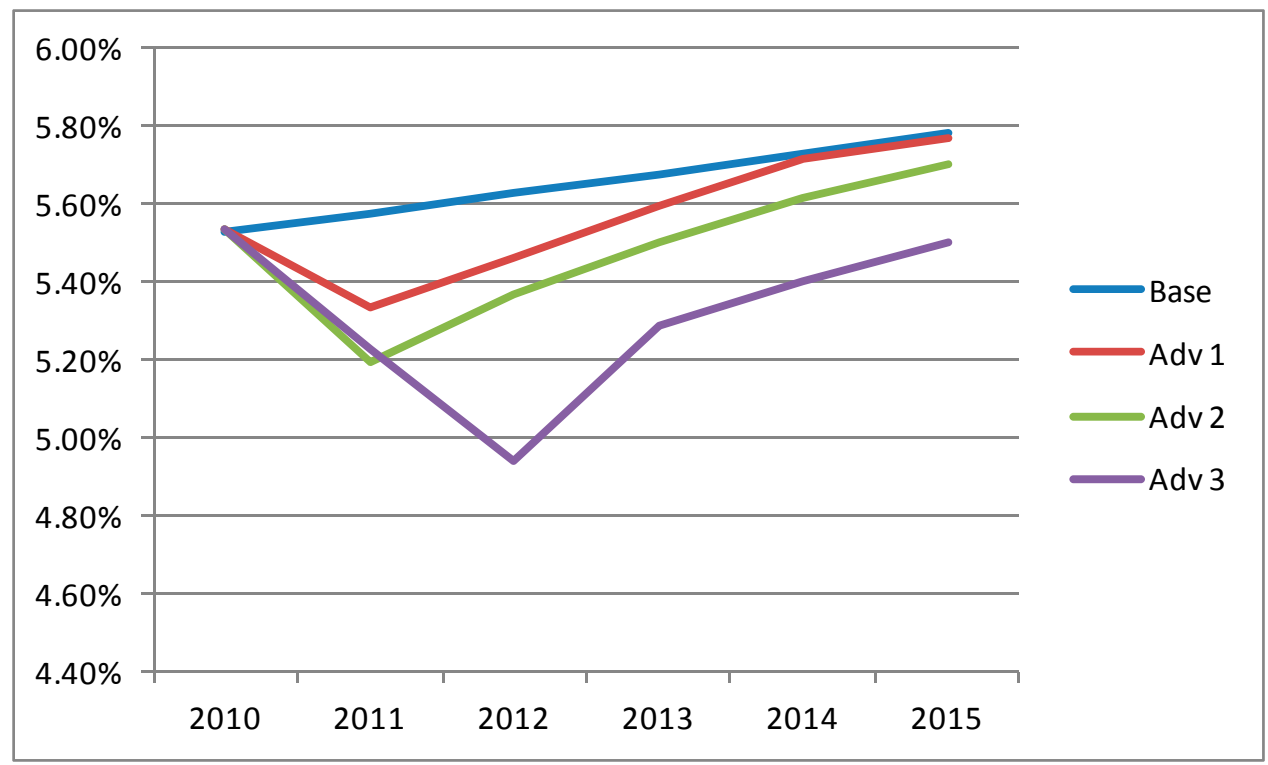

\footnotetext{
${ }^{6}$ Note that the CCA capital ratios are smaller than Tier 1 ratios, which are calculated with risk-weighted assets which are lower than market value of assets. In many cases, RWA are about half the level of book assets, so CCA capital ratios, when divided by about 0.5 , increase to the same range as Tier 1 , but there are obviously differences in definition of the regulatory capital ratios vs. market-based capital ratios.
} 
Figure 1b. Sweden: CCA Capital Ratio 2006 to 2015

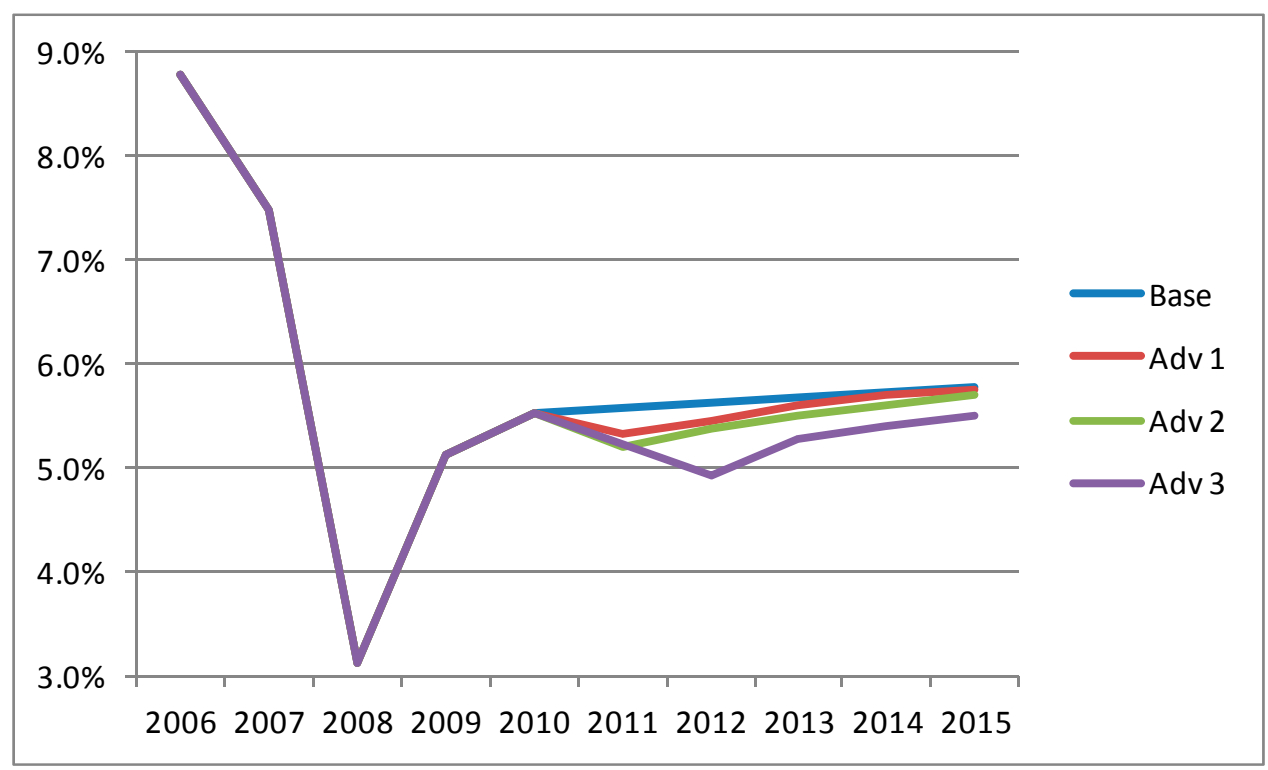

16. The simple sum of expected losses to bank creditors increases in the three adverse scenarios. They increase from SEK 88 billion at the end of 2010 to nearly SEK 140 billion in 2012 under the Adverse 1 scenario, and 180 billion under Adverse 2, but declines back to below SEK 100 billion in 2015 as shown in Figure 2. Under Adverse 3 scenario, expected losses increase to SEK 240 billion in 2012, but decline back to SEK 140 billion in 2015 . This is significantly lower than the sum of expected losses, which peaked at SEK 375 billion in 2009.

Figure 2. Sweden: Simple Sum of Expected Losses (SEK, billions)

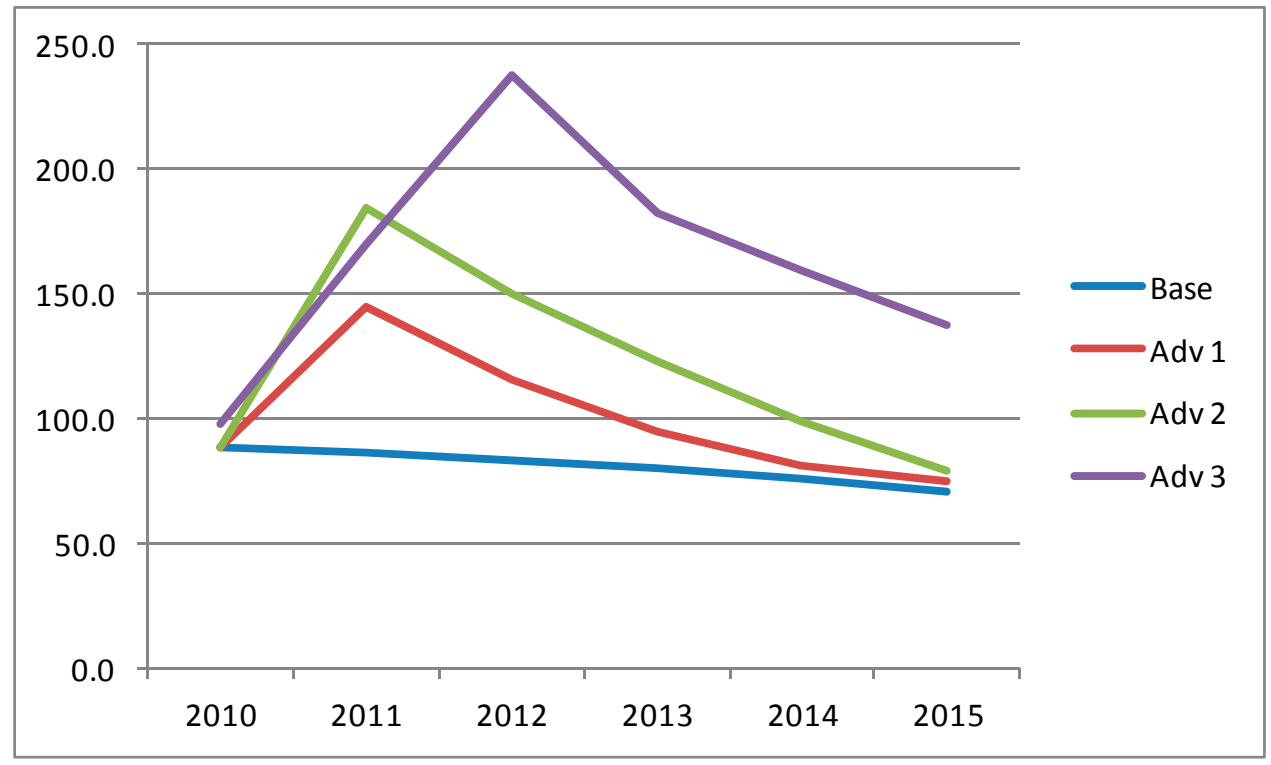


17. The one-year credit spreads, in basis points, are calculated for each scenario by taking the individual bank spreads and weighting them by the market value of assets of each bank. As shown in Figure 3, the weighted spreads rise from 95 bps to 145 bps under Adverse 1 scenario and 200 bps under Adverse 2 scenario in 2011-2012, but decline back under 100 bps by 2015 . Under the Adverse 3 scenario, spreads rise to 250 bps by 2012, but then decline back to 150 bps by 2015. Base case scenario spreads fall to 77 bps by 2015 .

Figure 3. Sweden: Credit Spreads (one year, basis points, weighted by bank assets)

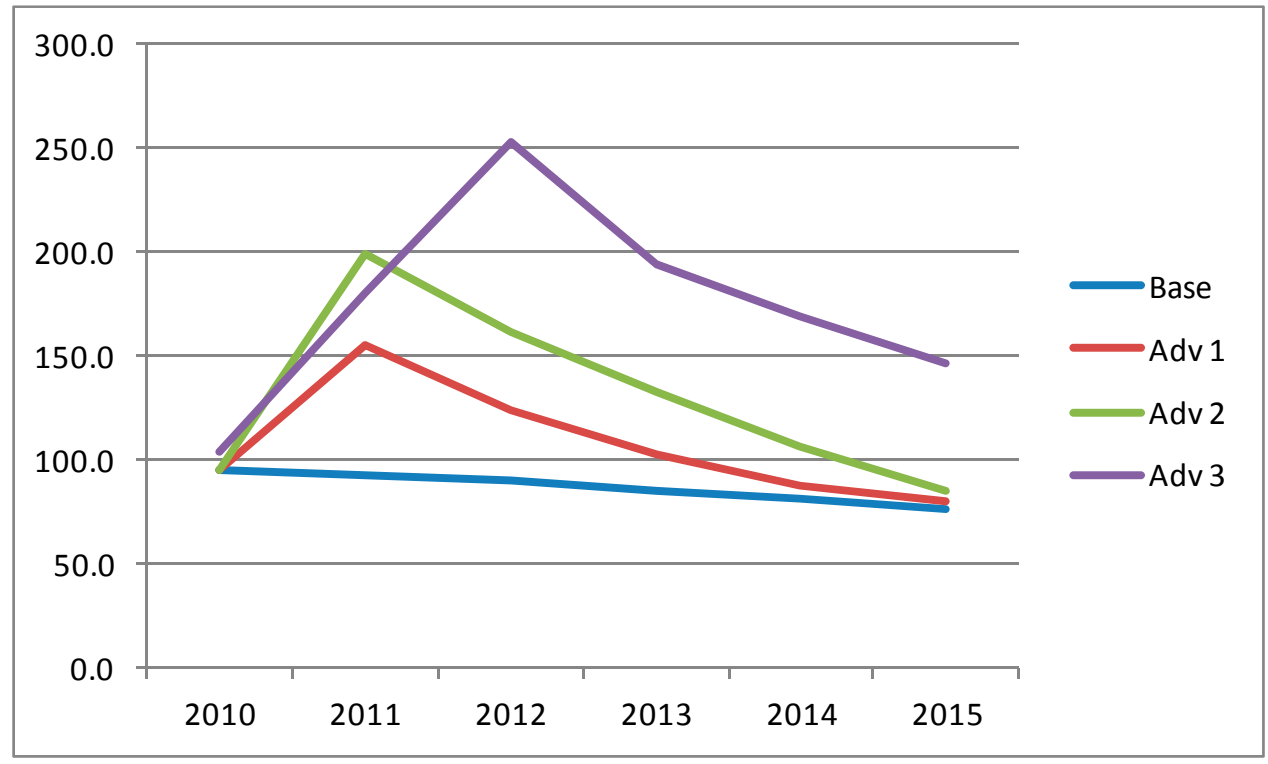

18. Bank-by-bank results are shown in Tables 1 and 2. The CCA capital ratios bank by bank for the base scenario are shown in Table 1; the ratios for all banks rise slightly each year from 2011 to 2015. In Table 2, the bank-by-bank results are shown for the three adverse scenarios. Expected losses to bank creditors and projected (market) value of equity capital are shown as a change (in percent) from the level in the base scenario (e.g., this is calculated as (EL for Adverse scenario 3 in year $\mathrm{x}$ minus EL for base scenario in year $\mathrm{x}$ )/EL for base scenario in year $\mathrm{x}$, reported in percent). Also reported in Table 2 is CCA capital ratio, which is market value of equity capital divided by market value of assets in percent (same units as in Table 1). As shown, expected losses increase the most in Adverse scenario 3 in 2012 for all banks, but end 79 to 110 percent higher in 2015. Under the Adverse 1 scenario the expected losses increase in 2011 and 2012, but end up on slightly higher than the base case in 2015 .

\section{The value of equity capital declines for all banks for all three adverse scenarios.}

Declines in the value of equity, relative to the base case, are largest in the early years but end up in 2015 with only a small decline under Adverse 1 scenario (ranging from no change to a decline of 0.75 percent). Under the Adverse 2 scenario, equity declines for the individual banks range from a decline of 1.51 percent to 2.26 percent. Under Adverse scenario 3, declines in equity range from a 
low of 3.08 percent (Bank 1) to a decline of 7.22 percent (Bank 4). CCA capital ratios, bank by bank, vary but show declines under Adverse scenario 3 in most cases in 2012. However, the ratios increase above 2011 levels by 2015, with largest increases under Adverse scenario 1.

Table 1. Sweden: CCA Capital Ratios for Base Scenario

(In percent)

\begin{tabular}{ccccc}
\hline & Bank 1 & Bank 2 & Bank 3 & Bank 4 \\
\hline 2010 & 6.17 & 5.44 & 5.56 & 4.99 \\
2011 & 6.24 & 5.48 & 5.60 & 5.02 \\
2012 & 6.31 & 5.53 & 5.65 & 5.06 \\
2013 & 6.38 & 5.58 & 5.69 & 5.10 \\
2014 & 6.45 & 5.64 & 5.73 & 5.14 \\
2015 & 6.51 & 5.69 & 5.78 & 5.18 \\
\hline
\end{tabular}

20. A measure of capital shortfall indicates that no bank has a capital shortfall under any scenario in any year. Regulatory capital and measures of market or CCA-based capital cannot be directly compared. But CCA measures of 'capital shortfall' can be computed. By defining a threshold above the default barrier, the value of the capital cushion above the default barrier up to the threshold can be calculated. The amount of market value of equity is then compared to this capital cushion, and if equity is larger than the capital cushion there is no capital shortfall. If, for example, we take a cushion equal to 4 percent of assets, none of the Swedish banks has a capital shortfall in any year under the four stress tests.

21. These results are consistent with the balance sheet stress test results. The outputs are: (i) expected losses to creditors; (ii) bank credit spreads; (iii) CCA capital ratio (market value of equity from the scenario output divided by the market value of assets); and (iv) capital shortfall measure. Results show that in the adverse scenarios, expected losses increase and equity capital decreases until 2012 and then reverse trend; however, the magnitude of the changes is much smaller than in 2009 during the financial crisis. The CCA capital ratios decline moderately (never falling below 4.9 percent, well above the low point of 3.1 percent ratio in 2009). Banks are found to be resilient to shocks. No bank has a capital shortfall in any year of the stress test (4 percent threshold). The results of the CCA analyses are consistent with the balance sheet stress test results. 
Table 2. Sweden: Expected Losses and Market Value of Equity (Percent change from Base Scenario) and CCA Capital Ratios (In percent)

\begin{tabular}{|c|c|c|c|c|c|c|c|}
\hline \multirow{7}{*}{ Adverse 1} & \multicolumn{4}{|c|}{ Bank 1} & \multicolumn{3}{|c|}{ Bank 2} \\
\hline & \multicolumn{2}{|c|}{ Exp Losses } & \multicolumn{2}{|c|}{ Equity Cap CCA Cap Ratio } & Exp Losses & Equity Cap & CCA Cap Ratio \\
\hline & 2011 & 92.06 & -3.08 & 6.05 & 63.01 & -4.71 & 5.23 \\
\hline & 2012 & 51.70 & -2.35 & 6.16 & 35.80 & -3.12 & 5.36 \\
\hline & 2013 & 22.57 & -1.24 & 6.30 & 15.81 & -1.54 & 5.50 \\
\hline & 2014 & 5.18 & -0.37 & 6.43 & 3.88 & -0.46 & 5.62 \\
\hline & 2015 & 0.76 & -0.39 & 6.50 & 1.04 & -0.41 & 5.67 \\
\hline & \multicolumn{4}{|c|}{ Bank 1} & \multicolumn{3}{|c|}{ Bank 2} \\
\hline \multirow[t]{7}{*}{ Adverse 2} & \multicolumn{2}{|c|}{ Exp Losses } & \multicolumn{2}{|c|}{ Equity Cap CCA Cap Ratio } & Exp Losses & Equity Cap & CCA Cap Ratio \\
\hline & 2011 & 155.11 & -4.02 & 5.99 & 104.55 & -7.72 & 5.06 \\
\hline & 2012 & 109.34 & -2.83 & 6.14 & 73.99 & -5.22 & 5.25 \\
\hline & 2013 & 73.46 & -2.12 & 6.26 & 49.89 & -3.52 & 5.40 \\
\hline & 2014 & 40.31 & -1.65 & 6.36 & 27.67 & -2.25 & 5.53 \\
\hline & 2015 & 14.56 & -1.55 & 6.44 & 10.28 & -1.51 & 5.62 \\
\hline & \multicolumn{4}{|c|}{ Bank 1} & \multicolumn{3}{|c|}{ Bank 2} \\
\hline \multirow[t]{7}{*}{ Adverse 3} & \multicolumn{2}{|c|}{ Exp Losses } & \multicolumn{2}{|c|}{ Equity Cap CCA Cap Ratio } & Exp Losses & Equity Cap & CCA Cap Ratio \\
\hline & 2011 & 117.80 & -4.13 & 5.98 & 99.42 & -7.12 & 5.10 \\
\hline & 2012 & 239.25 & -7.84 & 5.82 & 182.86 & -13.86 & 4.78 \\
\hline & 2013 & 160.39 & -3.97 & 6.14 & 129.06 & -8.15 & 5.15 \\
\hline & 2014 & 133.64 & -3.37 & 6.25 & 111.66 & -6.80 & 5.28 \\
\hline & 2015 & 108.69 & -3.08 & 6.34 & 95.34 & -5.72 & 5.40 \\
\hline & \multicolumn{4}{|c|}{ Bank 3} & \multicolumn{3}{|c|}{ Bank 4} \\
\hline \multirow[t]{7}{*}{ Adverse 1} & \multicolumn{2}{|c|}{ Exp Losses } & \multicolumn{2}{|c|}{ Equity Cap CCA Cap Ratio } & Exp Losses & Equity Cap & CCA Cap Ratio \\
\hline & 2011 & 73.97 & -4.08 & 5.38 & 62.55 & -5.54 & 4.75 \\
\hline & 2012 & 41.96 & -3.00 & 5.48 & 36.11 & -3.72 & 4.88 \\
\hline & 2013 & 19.02 & -1.69 & 5.60 & 26.94 & -1.61 & 5.03 \\
\hline & 2014 & 5.73 & -0.73 & 5.70 & 21.08 & -0.15 & 5.14 \\
\hline & 2015 & 2.89 & -0.75 & 5.75 & 20.71 & 0.00 & 5.19 \\
\hline & & & Bank 3 & & & Bank 4 & \\
\hline \multirow[t]{7}{*}{ Adverse 2} & \multicolumn{2}{|c|}{ Exp Losses } & Equity Cap & CCA Cap Ratio & Exp Losses & Equity Cap & CCA Cap Ratio \\
\hline & 2011 & 123.97 & -6.19 & 5.26 & 103.30 & -9.44 & 4.55 \\
\hline & 2012 & 88.06 & -4.50 & 5.41 & 74.23 & -6.66 & 4.74 \\
\hline & 2013 & 60.39 & -3.42 & 5.52 & 51.24 & -4.72 & 4.88 \\
\hline & 2014 & 35.37 & -2.66 & 5.61 & 29.86 & -3.17 & 5.00 \\
\hline & 2015 & 16.29 & -2.26 & 5.68 & 13.07 & -2.18 & 5.09 \\
\hline & & & Bank 3 & & & Bank 4 & \\
\hline Adverse 3 & & Losses & Equity Cap & CCA Cap Ratio & Exp Losses & Equity Cap & CCA Cap Ratio \\
\hline & 2011 & 99.97 & -6.01 & 5.28 & 74.03 & -7.79 & 4.64 \\
\hline & 2012 & 199.77 & -11.86 & 5.00 & 149.21 & -15.58 & 4.29 \\
\hline & 2013 & 138.40 & -7.39 & 5.30 & 101.85 & -9.65 & 4.63 \\
\hline & 2014 & 120.80 & -6.79 & 5.39 & 86.95 & -8.33 & 4.75 \\
\hline & 2015 & 104.93 & -6.37 & 5.46 & 72.94 & -7.22 & 4.85 \\
\hline
\end{tabular}

\section{Systemic CCA Analysis OF THE Swedish Banking System}

22. The Systemic CCA framework quantifies systemic financial sector risk. As a logical extension to the individual bank analysis, we evaluate the magnitude of systemic risk jointly posed 
by financial institutions. Such an approach allows us to determine expected and unexpected losses from systemic financial sector risk, as well as measures of extreme (or residual) risk. We apply the concept of extreme value theory (EVT) in order to specify a multivariate limiting distribution that formally captures the potential of extreme realizations of expected losses to creditors. See Appendix III for a short description of EVT. In order to assess systemic risk (and the underlying joint default risk), however, a simple summation of implicit put options would presuppose perfect correlation, i.e., a coincidence of defaults. While it is necessary to move beyond "singular CCA" by accounting for the dependence structure of individual balance sheets and associated contingent claims, the estimation of systemic risk through correlation becomes exceedingly unreliable in the presence of "fat tails." Correlation describes the complete dependence structure between two variables correctly only if the joint (bivariate) probability distribution is elliptical ${ }^{7}$-an ideal assumption rarely encountered in practice. This is especially true in times of stress, when default risk is highly skewed, and higher volatility inflates conventional correlation measures automatically (as covariance increases disproportionately to the standard deviation), so that large extremes may even cause the mean to become undefined. In these instances, default risk becomes more frequent and severe than suggested by the standard assumption of normality-i.e., there is a higher probability of large losses and more extreme outcomes.

\section{Accounting for both linear and nonlinear dependence between higher moments of changes in asset values can deliver important insights about the joint tail risk of multiple entities. Large shocks are transmitted across entities differently than small shocks. One way} forward is to view the financial sector as a portfolio of individual contingent claims (with individual risk parameters), whose joint implicit put option value is defined as the multivariate density of each financial institution's individual marginal distribution of expected losses to bank creditors and their time-varying dependence structure- the Systemic CCA approach (Gray and Jobst, 2010). As opposed to the traditional (pairwise) correlation-based approach, this method of measuring "tail dependence" is better suited to analyzing extreme linkages of multiple (rather than only two) entities, because it links the univariate marginal distributions of expected losses (and associated liabilities) in a way that formally captures both linear and nonlinear dependence in joint tail risk behavior over time. As an integral part of this approach, the marginal distributions fall within the domain of Generalized Extreme Value Distribution, GEV (Coles et al., 1999; Poon et al., 2003; Stephenson, 2003; Jobst, 2007). ${ }^{8}$ See Appendix III and IMF 2010b for more details.

\section{The Systemic CCA methodology to a sample of the four largest commercial banks in}

Sweden. Over a sample period from January 2007 to May 2010, we estimate the magnitude of implicit government guarantees for all banks and quantify the individual banks' contributions to

\footnotetext{
${ }^{7}$ Note that an elliptical joint distribution implies normal marginal distributions but not vice-versa.

${ }^{8}$ This approach is distinct from previous studies of joint patterns of extreme behavior. For instance, Longin (2000) derives point estimates of the extreme marginal distribution of a portfolio of assets based on the correlation between the series of individual maxima and minima (see Embrechts et al., 2001).
} 
government contingent liabilities in the event of a systemic bank distress ("tail risk"). For the individual CCA, we apply an enhanced version of the Merton framework, advanced CCA. Figure 4 shows the estimation results of the Systemic CCA-derived multivariate density of expected losses (i.e., full value of the implicit put option). The median of the multivariate distribution of losses and the 95 percent VaR (tail risk). Horizon period is one year. July and August 2009 was the peak (5 percent chance of losses of SEK 200 billion over the coming year).

Figure 4. Sweden: Banking Sector-Total Sum and Multivariate Distribution Function of Contingent Liabilities $\left(50^{\text {th }}\right.$ percentile and $95^{\text {th }}$ percentile)

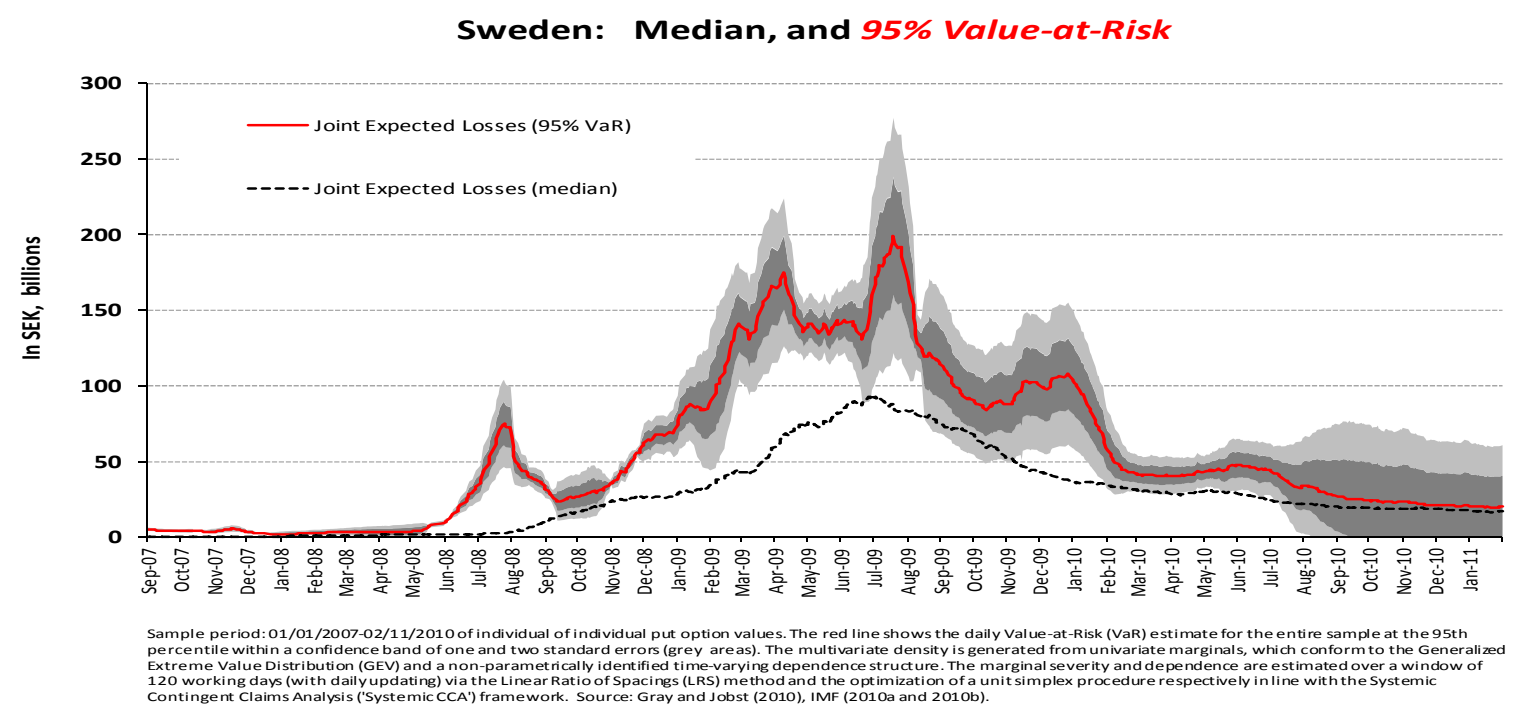

25. Joint losses from the stress test scenarios going forward are difficult to assess. High frequency data going forward would be the best way to assess joint expected losses from the stress test scenarios and such high frequency data is not available under this stress test. As a rough approximation, using past data as a guide, it is likely that the joint losses under the base case will be small (median losses of SEK 40 billion and $95^{\text {th }}$ percentile at SEK 70 billion). For the Adverse 3 scenario, joint losses will likely be higher (around SEK 80 billion for the median and SEK 120 to 150 billion for the $95^{\text {th }}$ percentile for 2012). This assumes a dependence structure similar to points in the crisis, which may not be the case in the future.

\section{Conclusions}

26. The balance sheet stress tests for the four major banks were complemented with tests based on the CCA framework. CCA is a risk-adjusted balance sheet framework where changes in bank assets are directly linked to changes in market value of bank equity and the expected losses to bank creditors. The CCA balance sheets of the four major Swedish banks were calibrated up to end2010. The results of the balance sheet stress tests were used to estimate changes in bank assets, and together with the impact from changes in global risk appetite, CCA outputs were calculated for the 
four scenarios over the 2011-2015 period. The outputs are: (i) expected losses to creditors; (ii) bank credit spreads; (iii) CCA capital ratio (market value of equity from the scenario output divided by the market value of assets); and (iv) a capital shortfall measure.

\section{Results show banks are found to be resilient to shocks; no bank has a capital shortfall}

in any year of the stress test. The results of the CCA analyses are consistent with the balance sheet stress test results. Results show that in the adverse scenarios, expected losses increase and equity capital decreases until 2012 and then reverse trend; however, the magnitude of the changes is much smaller than in 2009 during the financial crisis. The CCA capital ratios decline moderately.

Estimates of systemic risk indicate the systems stability has increased significantly since the crisis. Rough comparisons of stress test results to past systemic risks indicate a resilient system, but the correlation and dependence structure between banks is likely to be different in the future. More work on systemic risk models could help analyze systemic risk under stress scenarios. Future work should also focus on joint stress testing of the banking system and sovereign risk 


\section{ApPendix I: Contingent Claims AnALYsis}

28. Contingent claims analysis (CCA) is a generalization of the option pricing theory pioneered by Black-Scholes (1973) and Merton (1973). Since 1973, option pricing methodology has been applied to a wide variety of contingent claims. CCA is used to construct risk-adjusted balance sheets and is based on three principles: (i) the values of liabilities (equity and debt) are derived from assets; (ii) liabilities have different priority (i.e., senior and junior claims); and (iii) assets follow a stochastic process. Assets (present value of income flows, proceeds from assets sales, etc.) are stochastic and over a horizon period may be above or below promised payments on debt which constitute a default barrier. Uncertain changes in future asset value, relative to the default barrier, are the driver of default risk, which occurs when assets decline below the barrier. We first discuss the dynamics of default risk, initially without the CCA framework but then with the CCA model.

29. The CCA model assumes that the total market value of assets, $A$, at any time, $t$, is equal to the sum of its equity market value, $E$, and its risky debt, $D$. Asset value is stochastic and may fall below the present value of promised payments on debt, which constitute a default barrier, $\boldsymbol{B} .^{9}$ The value of risky debt is equal to default-free debt minus the present value of expected loss to creditors due to default. Default occurs when $A<B$. Equity value is the value of an implicit call option on the assets, with an exercise price equal to default barrier. The expected loss to bank creditors can be calculated as the value of an implicit put option, $P$, on the assets with an exercise price equal to $B$. The equity value, $E$, can be computed as the value of a call option:

$$
\begin{gathered}
E(t)=A(t) N\left(d_{1}\right)-B e^{-r T} N\left(d_{2}\right) \\
d_{1}=\frac{\ln \left(\frac{A}{B}\right)+\left(r+\frac{\sigma^{2}}{2}\right) T}{\sigma \sqrt{T}} \text { and } d_{2}=\frac{\ln \left(\frac{A}{B}\right)+\left(r-\frac{\sigma^{2}}{2}\right) T}{\sigma \sqrt{T}}
\end{gathered}
$$

where $r$ is the risk-free rate, $\sigma$ is the asset return volatility, and $N(d)$ is the cumulative probability of the standard normal density function below $d$. In its basic concept, the model assumes that the implicit options are of the European variety, and set the time until expiry, $T$ equal to the time horizon of interest, usually between one and five years.

The formula for the implicit put option is:

$$
P_{E}(t)=B e^{-r T} N\left(-d_{2}\right)-A(t) N\left(-d_{1}\right)
$$

\footnotetext{
${ }^{9}$ MKMV defines this barrier equal to total short-term debt plus one-half of long-term debt based on empirical studies.
} 
30. Several widely used techniques have been developed to calibrate the CCA models using a combination of balance sheet information and forward-looking information from equity markets. The market value of assets of corporations and financial institutions cannot be observed directly, but can be implied using financial asset prices. From the observed prices and volatilities of market-traded securities, one can estimate the implied values and volatilities of the underlying assets in financial institutions. In the traditional Merton (1974) model, the calibration requires knowledge about value of equity, $E$, the volatility of equity, $\sigma_{E}$, and the distress barrier as inputs into equations $E=A_{0} N\left(d_{1}\right)-B e^{-r T} N\left(d_{2}\right)$ and $E \sigma_{E}=A \sigma_{A} N\left(d_{1}\right)$ in order to calculate the two unknowns, the implied asset value $A$ and implied asset volatility $\sigma_{A} \cdot{ }^{10}$

\section{Once the asset value and asset volatility are known, expected losses to bank creditors} can be calculated. Asset value and asset volatility, together with the default barrier, time horizon, and the discount rate $r$, are used to calculate the values of the implicit put option, $P_{E}$, which is the expected loss to bank creditors.

32. The yield to maturity on the risky debt, $\mathrm{y}$, is defined by: $D=B e^{-y T}$

The credit spread is defined as $s=y-r,(r$ is the risk-free rate of interest $)$, thus

$$
\frac{D}{B}=e^{-y T}=e^{-s T} e^{-r T}, \text { and thus } e^{-s T}=\frac{D}{B e^{-r T}}=\frac{B e^{-r T}-P_{E}}{B e^{-r T}}=1-\frac{P_{E}}{B e^{-r T}}
$$

so the credit spread $s=-\frac{1}{T}\left(1-\frac{P_{E}}{B e^{-r T}}\right)$

This will allow us to calculate the impact on the banks incremental borrowing costs.

33. Numerical Example: Assuming that: asset value $A=\$ 100$, asset volatility $\sigma=0.40$ (40 percent), default barrier $B=\$ 75$, risk free rate $r=0.05$ (5 percent), $T=1$ (one year), the value of the equity is $\$ 32.367$, the value of risky debt is $\$ 67.633$; the yield to maturity on the risky debt is 10.34 percent, and the credit spread 5.34 percent or 534 basis points. The risk-neutral default probability, RNDP $\left(=N\left(-d_{2}\right)\right)$ is 26 percent.

34. The expected loss to bank creditors (the implicit put option $P_{E}$ ) formula can be broken down into its key components. The formula for the implicit put option can be rearranged and decomposed into the (i) risk-neutral default probability (RNDP); (ii) loss given default (LGD); and (iii) the value of the default-free value of debt (B).

\footnotetext{
${ }^{10}$ See Merton (1974, 1977, 1992), Gray, Merton, and Bodie (2008), as well as Gray and Malone (2008).
} 


$$
P_{E}=N\left({ }_{R N D P}\right) \underbrace{\left(1-\frac{N\left(-d_{1}\right)}{N\left(-d_{2}\right)} \frac{A}{B e^{-r T}}\right)}_{L G D} B e^{-r T},
$$

We can use the equations above to see that the spread can also be written as a function of the riskneutral default probability (RNDP) and LGD, i.e.,

$$
s=-\frac{1}{T} \ln (1-R N D P \times L G D)
$$

(Note that this BSM specification for the asset process described above does not incorporate skewness, kurtosis, and stochastic volatility, which can account for implied volatility smiles and skews of equity prices. For robustness, ${ }^{11}$ however, in this analysis we employ the closed-form Gram-Charlier model of Backus et al. (2004), which allows for kurtosis and skewness in returns and does not require market option prices to implement, but is constructed using the same diffusion process for stock prices as the Black-Scholes-Merton model. ${ }^{12}$ )

Impact of change in bank assets, associated change in asset volatility and the impact of changes in global risk appetite on expected losses to creditors and bank funding costs

35. When bank assets change due to profits, loan losses, tax and dividend payments, these create changes in the bank asset value. Changes in the asset, $A$, affect asset volatility, $\sigma_{A}$. We define the original asset before changes in value as $A$ and original asset volatility of $\sigma_{A}$. After the changes caused by inflows (profits), loan losses, and outflows (tax and dividend payments), the asset value is $A+\delta A$. In CCA models, when the asset declines the volatility increases, for the BSM formulas the relationship is $A \sigma_{A}=(A+\delta A) \sigma_{A+\delta A} \cdot{ }^{13}$ However, given we are not using just the BSM model (we use the GC model, which includes skew and kurtosis) we use the following relationship to calculate the revised, or new, volatility, $\sigma_{A+\delta A}$.

$$
\left(\frac{A}{A+\delta A}\right)^{-\gamma} \sigma_{A}=\sigma_{A+\delta A}
$$

\footnotetext{
${ }^{11}$ These results are not reported in this note, see Rouah p 124-129 for the Gram-Charlier model.

${ }^{12}$ Further refinements of this model would include various simulation approaches at the expense of losing analytical tractability. The Heston (1993) and Heston and Nandi (2000) models allow for stochastic volatility, but the parameters driving these models can be difficult to estimate. Other option pricing models such as Gram Charlier are easy to use, contain skew and kurtosis and are closed form.

${ }^{13}$ The reason that asset volatility goes up when the asset goes down is derived from Ito's Lemma for the original asset value A and the changed asset; the diffusion terms in the Ito's Lemma are equal and the result, for the Black-ScholesMerton geometric Brownian motion asset process, is that initial A times initial volatility = changed A times new volatility. See Chriss (1997). Simply put, the stochastic processes are closely related and the diffusion terms are equal.
} 
The parameter, $\gamma$, is calculated empirically from the observed relationship of implied asset values and implied asset volatility over the recent historical period (about one year).

\section{Another important factor that drives spreads of banks (as well as corporates and} sovereigns) and affects bank funding cost is change in global risk appetite. The market price of risk is an important parameter in CCA formulas, which changes when global risk appetite changes. It is a barometer that measures the level of risk appetite and is used to translate from the real to riskneutral default probability. In the CCA model developed by Moody's KMV, the market price of risk is empirically calculated. It uses the capital asset pricing model together with the CCA model to estimate the market price of risk (MPR) as, $\lambda=\rho_{A, M} S R$, where $\lambda$ is the market price of risk, $\rho_{A, M}$ is the correlation of the bank's asset return with the global market and $S R$ is the global market Sharpe ratio. ${ }^{14}$ The four stress test scenarios are associated with four scenarios for the market price of risk. An increase in the MPR is associated with a systemic increase in the average volatility of bank assets (including Swedish banks) and associated with an increase in the risk-neutral default probability and the expected losses to bank creditors. Appendix 2 provides the derivation and the details.

37. Changes in funding coasts come from the incremental funding cost. The incremental spread formula is $s_{\text {incremental }}=\left[-T^{-1} \ln \left(1-E L / B e^{-r T}\right)\right]-s_{\text {base }}$. Credit spread from the scenario (which is a function of expected loss, EL, bank default barrier, $\mathrm{B}$, risk free rate, $r$, and time horizon $\mathrm{T}$ equal to one year) minus the base credit spread (i.e., spread if bank assets remain unchanged) gives the incremental credit spread. This is multiplied by the incremental debt due each year to get the change in funding costs each year. These figures are adjusted for the percent of increased funding cost that can be transferred to customers, see Appendix 4 for the assumptions for each scenario and the debt due each year. The change in funding costs that cannot be passed on to customers corresponds to an additional change in bank assets and are inserted in the CCA model and the outputs are recalculated.

38. Adjusted asset plus adjusted volatility, inserted into CCA spread formula and applied to debt due in next year gives additional incremental funding cost changes year by year. The changes in the asset due to funding cost changes $\delta A_{F C}$ are added to the earlier changes. (The figures on debt due each year are in Annex 4.) These asset changes are added in and the volatility is revised again.

$$
\left(\frac{A}{A+\delta A+\delta A_{F C}}\right)^{-\gamma} \sigma_{A}=\sigma_{A+\delta A+\delta A_{F C}}
$$

39. The final outputs are: (i) expected losses to creditors; (ii) credit spreads; and (iii) CCA capital ratio (market value of equity from the scenario output divided by the market value of assets for the same scenario). The final results thus include the changes in assets (due to changes

\footnotetext{
${ }^{14}$ See Crouhy, Galai, and Mark (2000), Bohn (2000), MKMV (2003).
} 
in profits, loan losses, taxes, and dividends), associated changes in asset volatility, impact of the change in the market price of risk, and the impact of the incremental funding cost changes.

40. A measure of capital shortfall indicates the no bank has a capital shortfall under any scenario in any year. Regulatory capital and measures of market or CCA-based capital cannot be directly compared. But CCA measures of 'capital shortfall' can be computed. By defining a threshold above the default barrier, the value of the capital cushion above the default barrier up to the threshold can be calculated. The amount of market value of equity is then compared to this capital cushion, and if equity is larger than the capital cushion, there is no capital shortfall. If, for example, we take a cushion equal to 4 percent of assets, none of the Swedish banks has a capital shortfall in any year under the four stress tests. 


\section{Appendix II: CCA with the Market Price Of Risk}

\section{Modeling default risk}

\section{Let us start with the evolution of bank assets over time horizon $\mathbf{t}$ relative to the} promised payments on the debt (default-free value of the debt and deposits). The value of assets at time $\mathrm{t}$ is $A(t)$. The asset return process is $d A / A=\mu_{A} d t+\sigma_{A} \varepsilon \sqrt{t}$, where $\mu_{A}$ is the drift rate or asset return, $\sigma_{A}$ is equal to the standard deviation of the asset return, and $\varepsilon$ is normally distributed, with zero mean and unit variance. The probability distribution at time $T$ is shown in Figure 5(a) below.

Figure 5a. Sweden: Modeling Default Risk

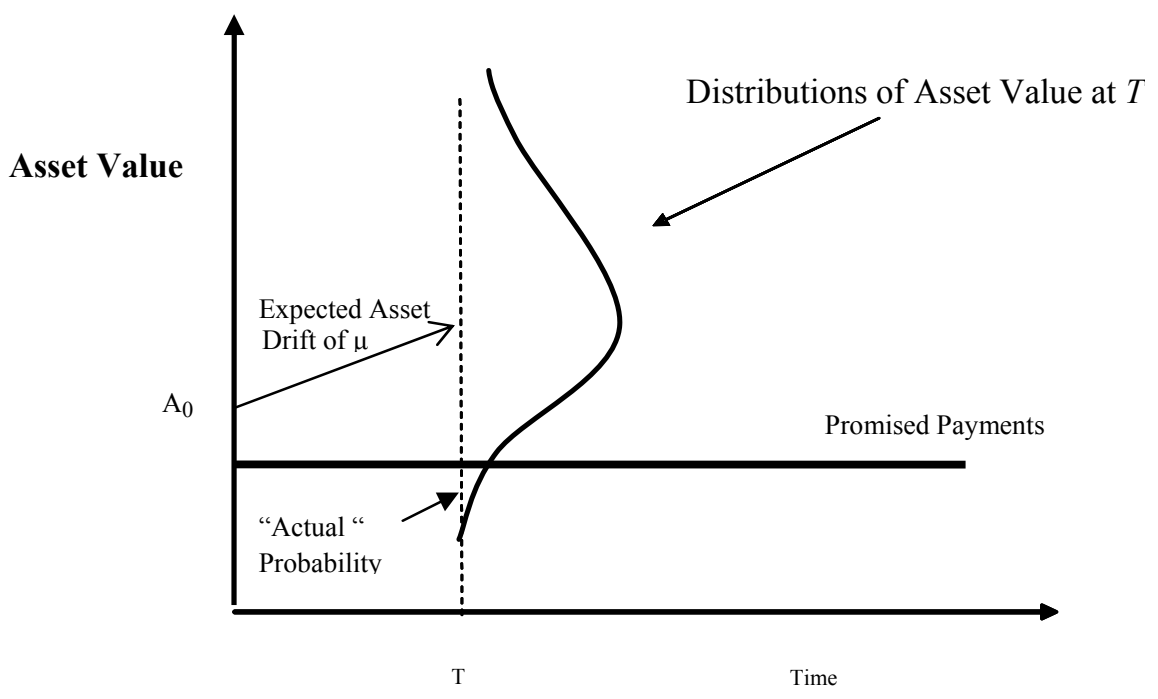

Default occurs when assets fall to or below the promised payments, $B_{t}$. The probability of default is $A_{t} \leq B_{t}$ so that

$$
\operatorname{Pr}\left(A_{t} \leq B_{t}\right)=\operatorname{Pr}\left(A_{0} \exp \left[\left(\mu_{A}-\sigma_{A}^{2} / 2\right) t+\sigma_{A} \varepsilon \sqrt{t}\right] \leq B_{t}\right)=\operatorname{Pr}\left(\varepsilon \leq-d_{2, \mu}\right) .
$$

Since $\varepsilon \square N(0,1)$, the "actual" probability of default is $N\left(-d_{2, \mu}\right)$, where $d_{2, \mu}=\left[\ln \left(A_{0} / B_{t}\right)+\left(\mu_{A}-\sigma_{A}^{2} / 2\right) t\right]\left(\sigma_{A} \sqrt{t}\right)^{-1}$. The "actual" probability of default is the area below the line (promised payment, i.e., the default barrier).

\section{Shown in Figure 5(b) below is the probability distribution (dashed line) with drift of} the risk-free interest rate $r$. The risk-adjusted probability of default is $N\left(-d_{2}\right)$. The area below the distribution in Figure 5(a) is the "actual" probability of default. The asset-return probability distribution used to value contingent claims is not the "actual" one but the "risk-neutral" probability distribution, which is the dashed line in Figure 5(b) with expected rate of return $r$, the risk-free rate. Thus, the "risk-neutral" probability of default is larger than the actual probability of default for all 
assets, which have an actual expected return $(\mu)$ greater than the risk-free rate $r$ (that is, a positive risk premium) ${ }^{15}$

Figure 5b. Sweden: Actual vs. Risk Neutral Default Probabilities

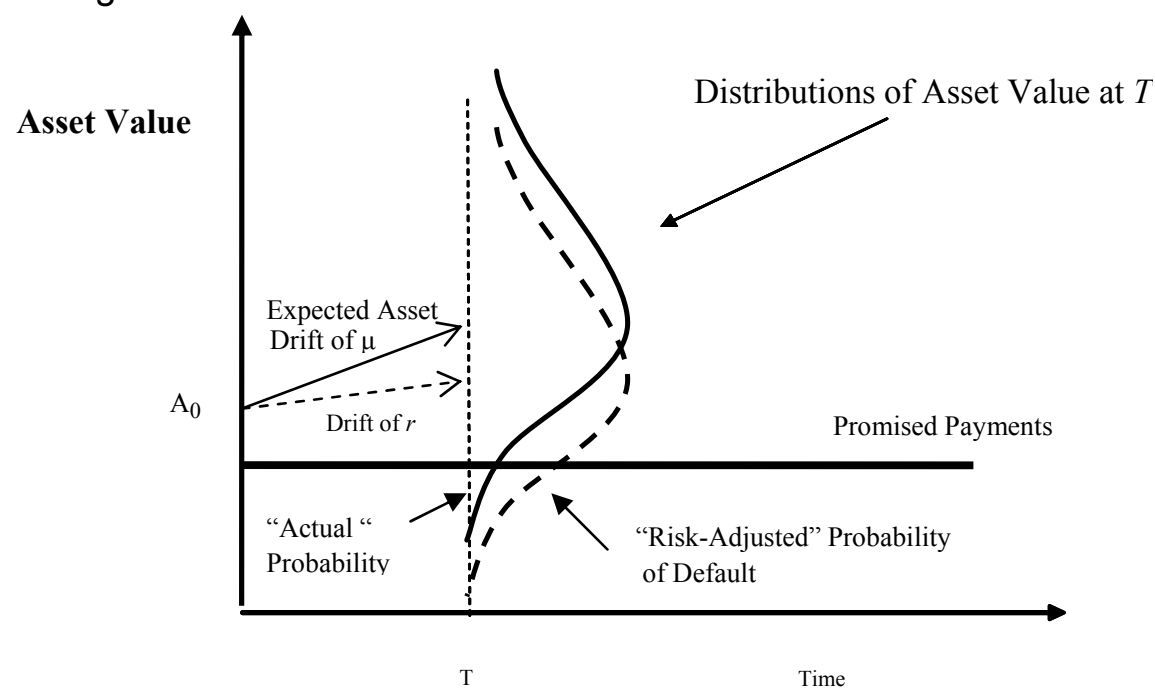

These two risk indicators are related by the market price of risk, $\lambda$ :

$$
N\left(-d_{2, \mu}\right)=N\left(-d_{2}-\lambda \sqrt{t}\right)
$$

43. The market price of risk reflects investors' risk appetite. It is the "wedge" between the real and risk-neutral default probability. It can be estimated in several ways. One way is the use of the capital asset pricing model (CAPM) model to estimate the market price or risk is shown in Box 1.

\section{Box 1. Market Price of Risk}

MKMV uses a two moment CAPM to derive the Market Price of Risk (MPR). CAPM states that the excess return of a security is equal to the beta $\beta$ of the security times the market risk premium $\left(\mu_{M}-r\right)$.

$$
\mu-r=\beta\left(\mu_{M}-r\right)
$$

Beta is equal to the correlation of the asset with the market times the volatility of the asset divided by the volatility of the market.

$$
\beta=\frac{\operatorname{cov}\left(r_{V}, r_{M}\right)}{\operatorname{var}\left(r_{M}\right)}=\rho_{A, M} \frac{\sigma_{A}}{\sigma_{M}} \quad \text { So, } \quad \mu-r=\rho_{A, M} \sigma_{A} \frac{\left(\mu_{M}-r\right)}{\sigma_{M}}=\rho_{A, M} \sigma_{A} S R
$$

Here $S R$ is the Market Sharpe Ratio (this number changes daily but is the same for all firms and financial institutions around the world), and thus $\frac{\mu-r}{\sigma_{A}}=\rho_{A, M} S R$

\footnotetext{
${ }^{15}$ See Merton (1992, pp.334-343; 448-450).
} 
Using the approach in Box 1 gives:

$$
\begin{gathered}
\lambda=\rho_{A, M} S R \quad \frac{\mu_{A}-r}{\sigma_{A}}=\lambda \\
\mu_{A}=r+\rho_{A, M} S R \sigma_{A}
\end{gathered}
$$

where $\rho_{A, M}$ is the correlation of the asset return with the market and $S R$ is the market Sharpe Ratio. According to MKMV data, $\rho_{A, M}$ is usually around 0.5 to 0.7 (calculated bank by bank in the MKMV Credit Edge model) and the $S R$ around 0.55 to 1.2 during the last few years. ${ }^{16}$ The main driver of the market price of risk in this model is the global Sharpe ratio. The correlation does not change much over time, but the SR changed considerably, see Figure 6 below.

Figure 6. Sweden: Global Sharpe Ratio

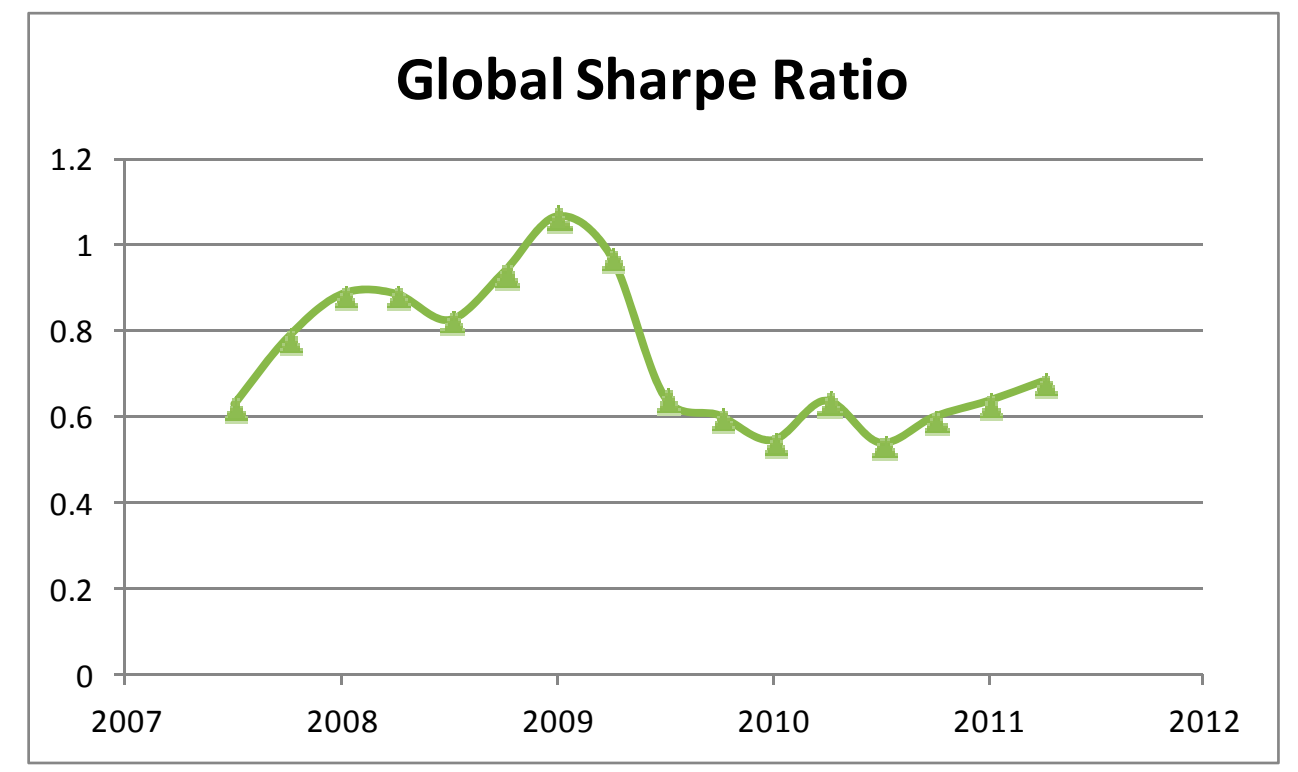

Higher global Sharpe ratio is associated with higher average volatility for Swedish banks. There is systemic impact on volatility in addition to the idiosyncratic change in volatility described in Appendix I. For the Swedish banks, average volatility is around 16 percent (annualized) when the Sharpe ratio is 0.6 , but increases to 23 percent when the Sharpe ratio reaches 1.1. This systemic increase in volatility is included in the scenarios, empirically the change in Sharpe ratio times 0.09 given the incremental change in volatility (measured as a fraction).

\section{Changes in risk appetite affect risk perceptions going forward, affecting the dynamics} of the market price of risk. The market price of risk, over a one-year horizon is $\lambda=\rho_{A, M} S R$ and it provides a way to translate between the actual default probability (EDF) and the risk-neutral default probability.

\footnotetext{
${ }^{16}$ See MKMV (2003), Crouhy, Galai, and Mark (2000).
} 


$$
E D F_{\text {risk-neutral }}=N\left(N^{-1}\left(E D F_{T}\right)+\rho_{A, M} S R\right) N\left(-D 2 D+\rho_{A, M} S R\right)=N(-D 2 D+\lambda)
$$

D2D is the distance to distress, $x$. This allows one to estimate the change in expected losses to creditors when the market price of risk changes from $\lambda$ to $\hat{\lambda}$.

$$
E L=N(-D 2 D+\lambda) * L G D^{*} B e^{-r t} \quad E \widehat{L}=N(-D 2 D+\hat{\lambda}) * L G D^{*} B e^{-r t}
$$

The change in $\mathrm{EL}=E \widehat{L}-E L$

During the financial crisis in 2008 and 2009 the market price of risk rose as GDP in countries around the world fell sharply, including in Sweden. In the stress test scenario analysis, for Adverse 3 scenario, it is assumed the declining GDP growth corresponds to a severe crisis for Sweden and other countries not dissimilar to the 2008 and 2009 crisis. Such a severe crisis would be associated with an increase in the market price of risk. The driver of the MPR is the global Sharpe ratio. The adverse scenarios described in the balance sheet stress test are related by their severity to changes in the market price of risk based roughly on information from the last crisis. The Adverse 3 scenario is assumed to be severe, but not quite as severe as the worst of the crisis in 2008-09. Note there is a relationship between Swedish GDP and the MPR (inverted axis) during the crisis. The market Sharpe ratio for Adverse scenario 3 is projected out to 2015 in Figure 7, and GDP declines are similar to the crisis. This gives a feel for the order of magnitude in changes in GDP and the Sharpe ratio.

Figure 7. Sweden: GDP and Sharpe Ratio (inverted axis)

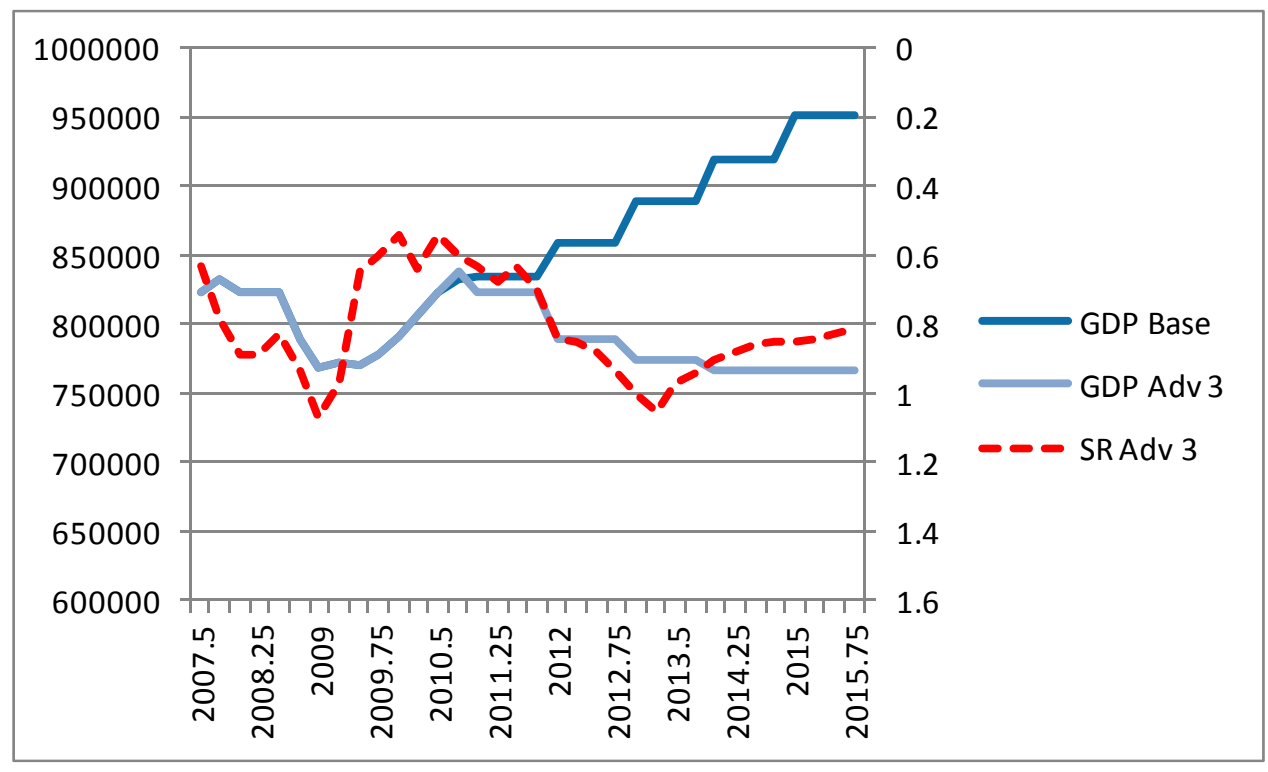


Figure 8 and Table 3 give the Sharpe ratio scenarios used in the CCA stress test analysis. The scenarios for the Sharpe ratio are projected to be roughly in line with the descriptions of the scenarios in the balance sheet stress tests, with Adverse 3 being the most severe.

Figure 8. Sweden: Market Sharpe Ratio Scenarios

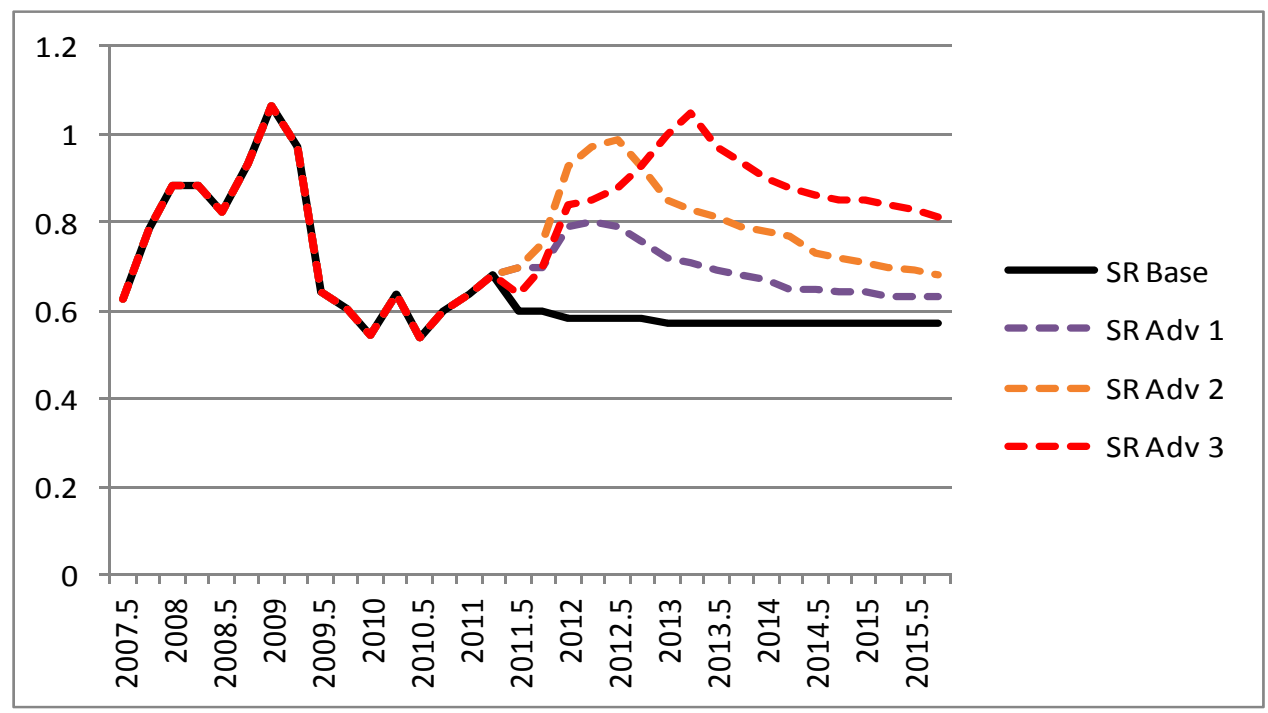

Table 3. Sweden: Market Sharpe Ratio Scenarios

\begin{tabular}{lcccc}
\hline & Base & Adv 1 & Adv 2 & Adv 3 \\
\hline 2010 & 0.63 & 0.63 & 0.63 & 0.63 \\
2011 & 0.58 & 0.79 & 0.93 & 0.84 \\
2012 & 0.57 & 0.72 & 0.85 & 1.00 \\
2013 & 0.57 & 0.67 & 0.78 & 0.90 \\
2014 & 0.57 & 0.64 & 0.71 & 0.85 \\
2015 & 0.57 & 0.63 & 0.68 & 0.80 \\
\hline
\end{tabular}




\section{APPENDIX III: SySTEMIC CCA}

45. The Systemic CCA framework is predicated on the quantification of the systemic financial sector risk from implicit guarantees to the financial sector in situations of market stress. We apply the concept of extreme value theory (EVT) in order to specify a multivariate limiting distribution that formally captures the potential of extreme realizations of expected losses to creditors.

\section{Financial stability and risk analysis must deal with extreme risks where there is a} small probability of extreme events to occur. Extreme value theory (EVT) is a branch of statistics that has been developed to analyze the probability if extreme values are occurring. Not surprisingly, EVT is quite different from the familiar 'central tendency' statistics, governed by 'central limit theorems' that most of us are familiar with. EVT uses different theorems and tells us how we should estimate the parameters of EV distributions. We are looking for probability distributions for the tail, i.e., for extreme events. Certain EV theorems tell us that the distribution of the extremes converges to a Generalized Extreme Value distribution (GEV):

$$
G=\left\{\exp \left[(1+\xi(x-\mu) / \sigma)^{-1 / \xi}\right] \text { if } \quad \xi \neq 0 \quad \text { and } \exp \left[-\exp \left(\frac{x-\mu}{\sigma}\right)\right] \quad \text { if } \quad \xi=0\right.
$$

where $1+\xi_{j}\left(x-\mu_{j}\right) / \sigma_{j}>0$, scale parameter of the limiting distribution is $\sigma_{j}>0$, location parameter of the limiting distribution $\mu_{j}$, and shape parameter. $\xi_{j}$ The higher the absolute value of shape parameter, the larger the weight of the tail and the slower the speed at which the tail approaches its limit. EVT can be used to specify the limiting distribution. It is general, it converges to other known distributions depending on whether the shape parameter is equal to zero, above zero, or below zero. Linkages between the distributions, say, for the losses of banks during periods of stress, can be measured with a dependence measure A. Let's look at the case of dependence between two distributions. $G_{B i \text { var iate }}=\exp \left\{-\left(y_{1}+y_{2}\right) A\left(y_{1} /\left(y_{1}+y_{2}\right)\right)\right\}$ The univariate marginal distribution s are $y_{j}\left(x_{j}\right)=\left(1+\xi_{j}\left(x-\mu_{j}\right) / \sigma_{i}\right)^{-1 / \xi_{j}}$ (for $\left.j=1, \ldots, m\right)$. We can go beyond the dependence between two distributions and use many, and get multivariate dependence. We apply the concept of extreme value theory (EVT) in order to specify a multivariate limiting distribution that formally captures the potential of extreme realizations of expected losses to creditors. (We specify the multivariate dependence structure of joint tail risk as the function $A\left(\omega_{1}, \ldots, \omega_{m-1}\right)$, which is derived nonparametrically by expanding the bivariate logistic method proposed by Pickands (1981) to the multivariate case and adjusting the margins according to Hall and Tajvidi (2000)). For the detailed formulas used for the Systemic CCA see the IMF US FSAP (IMF 2010b), and Gray and Jobst 2010.

\section{Since this approach also considers the time variation of point estimates due to a} periodic updating, it is more comprehensive than alternative measurement approaches to systemic risk. Other approaches are CoVaR (Adrian and Brunnermeier, 2008), CoRisk (Chan-Lau, 
2010), and Systemic Expected Shortfall (SES) (Acharya et al., 2009) (as well as extensions thereof, such as Huang et al., 2009). Neither approach applies multivariate density estimation like Systemic CCA, which allows the determination of the marginal contribution of an individual institution to concurrent changes of both the severity of systemic risk and the dependence structure across any combination of sample institutions for any level of statistical confidence and at any given point in time. By accounting for the dependence structure of individual bank balance sheets and associated contingent claims, this approach can be used to quantify the contribution of specific institutions to the dynamics of the components of systemic risk (at different levels of statistical confidence) ${ }^{17}$ In contrast, CoVaR, CoRisk, and SES examine incremental effects that cover only a fraction of available data that could be usefully integrated to assess the system-wide sensitivity of individual default risk of banks (and the associated cost to governments upon realization states of distress).

\footnotetext{
${ }^{17}$ The contribution to systemic (joint tail risk) is derived as the partial derivative of the multivariate density relative to changes in the relative weight of the univariate marginal distribution of each bank at the specified percentile. More specifically, the total expected shortfall (ES) can be written as a linear combination of the expected shortfalls of individual contingent liabilities, where the relative weights (in the weighted sum) are given by the second order cross partial derivatives of the inverse of the joint probability density function to changes in both the dependence function and the marginal distribution of individual contingent liabilities (see Annex 3).
} 
Appendix IV: Funding Cost Using CCA ANd DebT DUE EACH YeAR

Table 4. Sweden: Debt Due Each Year

\begin{tabular}{llllll}
\hline Billion SKr & & & & & \\
\hline Nordea Bank AB & 470.9 & 714.1 & 492.6 & 518.6 & 550.9 \\
Skandinaviska Enskilda Banken AB & 328.8 & 327.8 & 298.0 & 291.8 & 279.7 \\
Svenska Handelsbanken AB & 438.1 & 540.2 & 465.5 & 459.3 & 465.4 \\
Swedbank AB & 328.6 & 335.6 & 297.8 & 297.1 & 274.5 \\
\hline
\end{tabular}

Source: Bloomberg.

48. The incremental funding cost spread formula is $s_{\text {incremental }}=\left[-T^{-1} \ln \left(1-E L / B e^{-r T}\right)\right]-s_{\text {base }}$ this is multiplied by the incremental debt due each year. These incremental additional funding costs (positive or negative) are adjusted for the percent of funding cost that can be transferred to customers. As described in the balance sheet stress test TN, for Adverse scenario 1, 80 percent of funding cost can be transferred to customers so only 20 percent of the incremental funding costs is subtracted from the bank asset value. For Adverse scenario 2, 85 percent of funding cost can be transferred to customers and for Adverse scenario 1, 95 percent can be transferred. For the base scenario it is assumed all funding costs can be transferred so none of the incremental funding cost is subtracted from assets. Once the funding cost adjustments are made, the expected losses to bank creditors of the banks are re-estimated and thus provide outputs of the CCA and then aggregated to produce results for the Systemic CCA model. 


\section{REFERENCES}

Acharya V.V., Pedersen L., Philippon T. and M. Richardson, 2009, "Regulating Systemic Risk," in: Acharya, V .V. and M. Richardson (eds.). Restoring Financial Stability: How to Repair a Failed System. New York: Wiley.

Adrian, T. and M. K. Brunnermeier, 2008. "CoVaR," Staff Reports 348, Federal Reserve Bank of New York.

Bakshi, G., Cao, C., and Z. Chen, 1997, "Empirical Performance of Alternative Option Pricing Models," Journal of Finance, Vol. 52, No. 5, pp. 2003-2049.

Black F. and M. Scholes, 1973, “The Pricing of Options and Corporate Liabilities,” J. Polit. Econ., Vol. 81, No. 3, pp. 637-54.

Bohn, J. (2000) An Empirical Assessment of a Simple Contingent Claims Model for the Valuation of Risky Debt, Journal of Risk Finance, 1, 55-77.

Chriss, N., 1997. Black-Scholes and Beyond: Option Pricing Models. Chicago, IL: Irwin Professional Publishing.

Coles, S. G., Heffernan, J. and J. A. Tawn. 1999, "Dependence Measures for Extreme Value Analyses," Extremes, Vol. 2, pp. 339-65.

Cox, J.C., Ross, S.A., and M. Rubinstein, 1979, “Option Pricing: A Simplified Approach,” Journal of Financial Economics, Vol. 7, No. 3, pp. 229-263.

Crouhy, M., D. Galai, and R. Mark. (2000) Risk Management, McGraw Hill, New York.

Dumas,D., Fleming, J., and R.E. Whaley, 1998, "Implied Volatility Functions: Empirical Tests," Journal of Finance, Vol. 53, No. 6, pp. 2059-2106.

Embrechts, Paul, Lindskog, F. and A. McNeil, 2001, "Modelling Dependence with Copulas and Applications to Risk Management,” Preprint, ETH Zurich.

Gray, D. F., 2009, "Modeling Financial Crises and Sovereign Risk,” Annual Review of Financial Economics (edited by Robert Merton and Andrew Lo)," Annual Reviews, Palo Alto California, USA.

,and A. A. Jobst, 2009, "Higher Moments and Multivariate Dependence of Implied Volatilities from Equity Options as Measures of Systemic Risk," Global Financial Stability Report, Chapter 3, April (Washington: International Monetary Fund), pp. 128-131. 
,and A. A. Jobst, 2010, "New Directions in Financial Sector and Sovereign Risk Management, Journal of Investment Management, Vol. 8, No.1, pp. 23-38.

,and A. A. Jobst, forthcoming, "Systemic Contingent Claims Analysis (Systemic CCA) —Estimating Potential Losses and Implicit Government Guarantees to Banks," IMF Working Paper (Washington: International Monetary Fund), forthcoming.

,and S. Malone. 2008. Macrofinancial Risk Analysis. New York: Wiley.

,Merton R. C. and Z. Bodie, 2008, “A New Framework for Measuring and Managing Macrofinancial Risk and Financial Stability,” Harvard Business School Working Paper No. 09-015.

Haldane, Andrew G., 2011, "Capital Discipline," paper based on a speech given at the American Economic Association, Denver, United States, January.

Hall, P. and N. Tajvidi, 2000, "Distribution and Dependence-function Estimation for Bivariate Extreme Value Distributions," Bernoulli, Vol. 6, pp. 835-844.

Heston, S. L., 1993, “A Closed-Form Solution for Options with Stochastic Volatility with Applications to Bond and Currency Options," Review of Financial Studies, Vol. 6, No. 2, pp. 327-343.

,and S. Nandi, 2000, "A Closed-Form GARCH Option Valuation Model," Review of Financial Studies, Vol. 13, No. 3, pp. 585-625.

Huang, X., Zhou, H. and H. Zhu, 2010, "Assessing the Systemic Risk of a Heterogeneous Portfolio of Banks during the Recent Financial Crisis," Working paper (January 26), 22nd Australasian Finance and Banking Conference 2009 (available at http://ssrn.com/abstract=1459946).

Hull, J. C., 2006. Options, Futures, and Other Derivatives, Sixth Edition. Upper Saddle River, N.J.: Prentice Hall.

International Monetary Fund, 2008a, "Global Financial Stability Report: Containing Systemic Risks and Restoring Financial Soundness," World Economic and Financial Surveys (Washington: International Monetary Fund)

,2010a, Sweden Art IV, Selected Issues Paper, (Washington: International Monetary Fund)

,2010b, United States Financial Sector Assessment Program Technical Note on Stress Testing, July, (Washington: International Monetary Fund). 
, 2011 (draft, forthcoming), Sweden Financial Sector Assessment Program Update, Technical Note on Stress Testing of the Banking Sector, July, (Washington: International Monetary Fund).

Jobst, A. A., 2007, "Operational Risk-The Sting is Still in the Tail But the Poison Depends on the Dose," Journal of Operational Risk, Vol. 2, No. 2 (Summer), pp. 1-56. Also published as IMF Working Paper No. 07/239 (Washington: International Monetary Fund).

Khandani, A., Lo, A. W., and R. C. Merton, 2009, "Systemic Risk and the Refinancing Ratchet Effect," Harvard Business School, Working paper, pp. 36f.

Merton, R. C., 1973, “Theory of Rational Option Pricing,” Bell J. Econ. Manag. Sci., 4 (Spring), pp. 141-83.

,1974, "On the Pricing of Corporate Debt: The Risk Structure of Interest rates," $J$.

Finance 29 (May), pp. 449-70.

,1977, "An Analytic Derivation of the Cost of Loan Guarantees and Deposit Insurance: An Application of Modern Option Pricing Theory," Journal of Banking and Finance, Vol. 1, pp. 3-11.

Moody’s KMV (2003) Modeling Default Risk, KMV Corp.

Pickands, J., 1981, "Multivariate Extreme Value Distributions," Proc. $43^{\text {rd }}$ Sess. Int. Statist. Inst., 49, pp. 859-878.

Poon, S.-H., Rockinger, M. and J. Tawn, 2003, "Extreme Value Dependence in Financial Markets: Diagnostics, Models, and Financial Implications," The Review of Financial Studies, Vol. 17, No. 2, 581-610.

Rouah, F. and G. Vainberg. (2007) Option Pricing Models and Volatility, Wiley Finance, New Jersey.

Tarashev, N., C. Borio, and K. Tsatsaronis, 2009, "The Systemic Importance of Financial Institutions,” BIS Quarterly Review, September, pp. 75-87.

Vandewalle, B., Beirlant, J. and M. Hubert, 2004, "A Robust Estimator of the Tail Index Based on an Exponential Regression Model," in Hubert, M., Pison, G., Struyf, A. and S. Van Aelst (eds.) Theory and Applications of Recent Robust Methods (Series: Statistics for Industry and Technology). Birkhäuser, Basel, 367-76 (available at: http://www.wis.kuleuven.ac.be/stat/Papers/tailindexICORS2003.pdf). 